J. Lake Sci. (湖泊科学), 2011, 23(4): 498-504

http: //www.jlakes.org. E-mail : jlakes@niglas.ac.cn

(c) 2011 by Journal of Lake Sciences

\title{
强化生态浮床原位修复技术对污染河流浮游动物群落结构的影响”
}

\author{
杨风娟 ${ }^{1}$,杨 扬 ${ }^{1,2, * *}$, 潘 鸿 $^{1}$, 阿 丹 $^{1}$, 李 丽 $^{1}$, 乔永民 ${ }^{1}$, 钟 铮 $^{1}$ \\ ( 1 : 暨南大学水生生物研究所,广州 510632) \\ $(2$ :热带亚热带水生态工程教育部工程研究中心,广州 510632)
}

\begin{abstract}
摘 要: 对强化生态浮床原位修复技术修复南方重污染感潮河流过程中浮游动物的种群动态变化进行研究, 探讨浮游动 物群落结构变化特征与河流水质改善状况的相互关系. 结果显示, 经强化生态浮床处理后, 重污染感潮河流水质得到改 善, 浮游动物的种类由修复工程实施前的 5 种增加到 49 种, 且由单一耐污种转变为多种种类共存; 示范区各月浮游动物 个体丰度较对照区都有极显著增加 $(P<0.01)$, 由修复前最低 $1.22 \mathrm{ind} . / \mathrm{L}$, 达到示范区最高 $47.19 \mathrm{ind} . / \mathrm{L}$; 示范区的多样 性指数也有显著提高, 其中 Shannon-Wiener 多样性指数 $\left(H^{\prime}\right) 、$ Margalef 种类丰富度指数 $(D)$ 由初始的 $1.27 、 2.22$, 分别提 高到 1.62 和 3.12 . 本研究中示范区表现出了比对照区更强的浮游动物多样性恢复能力, 表明强化生态浮床原位修复技 术的应用在提升受污水体的生态恢复效能方面取得了显著的功效.
\end{abstract}

关键词 : 浮游动物 ; 群落结构;强化生态浮床;感潮河流

\section{Effect of an enhanced ecological floating bed (EEFB) on zooplankton community in a polluted river}

\author{
YANG Fengjuan, YANG Yang, PAN Hong, A Dan, LI Li, QIAO Yongmin \& ZHONG Zheng \\ (1: Research Center of Hydrobiology, Jinan University, Guangzhou 510632, P. R. China) \\ (2: Ministry of Education Engineering Research Center of Tropical and Subtropical Aquatic Ecological Engineering, Guang- \\ zhou 510632 , P. R. China)
}

\begin{abstract}
This paper studied the dynamic variation of zooplankton population during the process of in-situ restoration of a heavily polluted tidal river in southern China by the technology of enhanced ecological floating bed ( EEFB) and explored the changing characteristics of zooplankton community structure responding to the river water quality improvement. The results showed that the river water quality was improved after treated by EEFB, and the species of zooplankton increased from 5 to 49 and there occurred co-existence of multiple species instead of single pollution resistant species after implementing the restoration engineering. There was also a significant rise $(P<0.01)$ of monthly zooplankton richness, namely, increasing from the lowest 1.22 ind. $/ \mathrm{L}$ to the highest 47.19 ind. / L after the restoration work in the demonstration area comparing to the control area. The diversity index also achieved notable increase, of which Shannon-Wiener diversity index $\left(H^{\prime}\right)$ and Margalef species richness index $(D)$ increased from the original 1.27 and 2.22 to 1.62 and 3.12 , respectively. In the demonstration area zooplankton diversity showed higher recovery ability than that in the control area which indicated that the employment of in-situ restoration technology of EEPB was effective in raising the ecological recovery efficiency of polluted water bodies.
\end{abstract}

Keywords: Zooplankton; community structure; enhanced ecological floating bed; tidal river

水体污染、断流与生态破坏是我国河流面临的主要生态环境问题 ${ }^{[1]}$. 珠江流域, 尤其是珠江三角洲经济 发达地区和流经城镇的河流, 由于污染物的大量排放和不合理的土地利用方式, 导致了河流水体的严重污 染和生态破坏, 河流的生态功能丧失或者无法正常发挥. 同时, 河道的水质恶化对供水水源地的水生生态系 统产生了诸多有害影响,威胁着地区的饮用水安全. 依据河流生态系统特性和污染物迁移转化降解的机理,

* 国家水体污染控制与治理科技重大专项(2008ZX07211-003,2009ZX07211-009)资助. 2011-04-08 收稿;201104-29 收修改稿. 杨凤娟,女,1984 年生,硕士研究生;E-mail : yangjuan0609@ 126. com.

** 通讯作者; E-mail: yangyang@ scies. org. 
要治理河流污染和恢复河流生态系统功能,消除污染源或大量削减污染物的排放以及恢复河流应有的自然 物理结构是最根本的措施 ${ }^{[2]}$. 因此, 采用有效的技术措施, 对污染河流水体进行直接净化和修复, 对于改善 河流生态环境,恢复河流生态系统的功能显得尤为迫切.

利用基质填料和水生植物构建的强化生态浮床工艺, 是在人工湿地和植物浮床技术基础上发展起来 的一种比较新的生态工程化原位修复和控制技术 ${ }^{[3]}$. 其通过过滤、吸附、沉淀、离子交换、植物吸收和微生 物代谢等多种途径, 不仅可以直接从水体中去除污染物; 而且对废水进行原位处理, 缓解了土地紧张的矛 盾; 并因为其良好的漂浮性能和抗冲击负荷能力, 可适应各种水深和高污染水体, 且投资运行费用低、维 护管理方便,已引起人们广泛关注 ${ }^{[4]}$. 目前, 强化生态浮床系统在我国的研究和应用日益增多, 其水质净 化效果也得到普遍认可 ${ }^{[5-7]}$. 生态浮床对受污染河流进行修复, 强调的不仅是水质改善, 更重要的是通过 人工修复, 达到恢复河流自有生态系统循环的目标. 其中浮游动物作为河流生态系统食物链的中间环节, 部分类群可以反映水体的污染状况,在水体生态系统中起着重要作用 ${ }^{[8]}$. Mialet 等 $^{[9]}$ 对比利时斯凯尔特河 口进行长达 14 年的监测, 指出浮游动物的种类组成及丰度与水质状况的优劣程度关系密切; 吴振斌等 ${ }^{[10]}$ 的研究显示水质状况的好转, 使得浮游动物群落发生由耐污种群 (臂尾轮虫类 (Brachionus sp.) 、龟甲轮虫 类 (Keratella sp. )) 逐渐向寡污种群 (罗氏腔轮虫 (Lecane ludwigii)、柱足腹尾轮虫 (Gastropus stylifer)) 转变的 过程. 已有的研究多侧重于浮游动物群落结构与水质状况方面的评价, 对于生态工程技术 (尤其是浮床技 术) 修复重污染水体过程中浮游动物群落的动态变化及其响应, 并以此预测生态修复效能的研究还鲜有 报道.

本研究利用强化生态浮床技术对我国南方污染物浓度高,流速、流向、水位等发生周期性变化的感潮河 流进行原位修复, 通过对浮游动物群落结构和生物多样性变化趋势的研究, 重点探讨浮游动物种群变化与 河流水质改善间的响应关系,并从浮游动物角度来评价水体修复措施的可行性和有效性. 初步揭示河流由 单纯的水质恢复发展到对河流生态系统整体恢复的变化规律,为发展适合南方重污染感潮河流特点的水质 改善和生态修复的新技术提供理论依据, 为我国河流的管理从以改善水质为重点,拓展到河流生态系统恢 复的策略性转变提供科学依据.

\section{1 材料与方法}

\section{1 试验系统}

研究地点位于广东省佛山市珠江上游汾江河南海 $\mathrm{L}$ 河涌 $\left(23^{\circ} 03^{\prime}-23^{\circ} 04^{\prime} \mathrm{N}, 113^{\circ} 02^{\prime}-113^{\circ} 03^{\prime} \mathrm{E}\right)$, 属感 潮型河流. 河涌全长 $1700 \mathrm{~m}$, 常水位时河涌上中游约宽 $18-20 \mathrm{~m}$, 河水流速为 $0.02-0.06 \mathrm{~m} / \mathrm{s}$. 受到自然因素 的影响, $\mathrm{L}$ 涌枯水期基流量小, 水流流向顺逆不定, 每天随潮汐涨落; 作为城市纳污河的往复流, 水体污染物 浓度大, 水动力不足, 很难排人外江, 实现与外界的交换, 从而导致了该涌自净时间和空间不足,生态系统极 度脆弱,自净能力基本丧失.

从 2009 年 4 月初开始在 L 河涌上中 游河段两侧放置浮床, 开始实施两岸各长 $350 \mathrm{~m}$ 、覆盖率 $29 \%-33 \%$ 的生态浮床原位 修复工程.生态浮床由高密度聚乙烯材料 制成的浮床单体构成, 该单体面积为 $0.33 \mathrm{~m} \times 0.33 \mathrm{~m}$,材料制作采取抗氧化抗紫 外技术处理,具有使用寿命长 (大于 6 年), 不易造成二次污染等特点; 中间有一孔径 为 $0.12 \mathrm{~m}$, 深 $0.15 \mathrm{~m}$ 的植物栽种篮 (可拆 卸), 向其中填加砾石等填料, 固定植物之 余可达到强化净化效果的目的. 每 60 个浮 床单体以 PVC 管件拼装为一个 $1.65 \mathrm{~m} \times$ $3.96 \mathrm{~m}$ 的矩形床, 按单个矩形浮床种植同

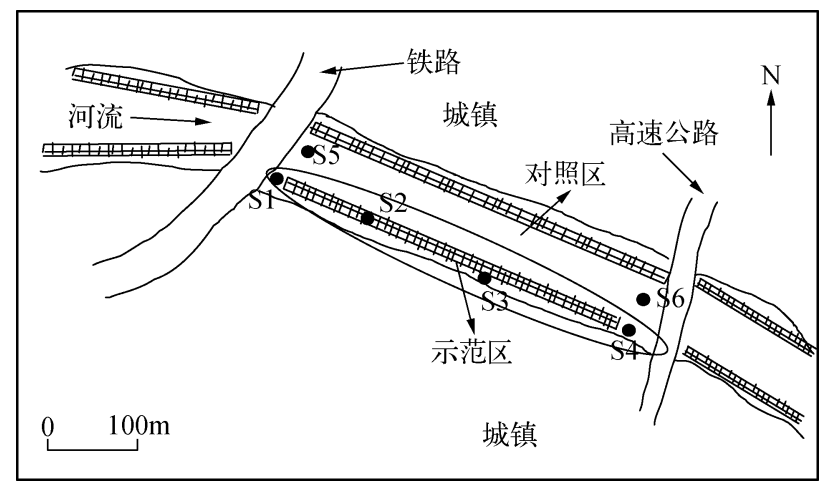

图 1 研究区域与采样点

Fig. 1 Study area and sampling sites 
种植物, 在其中种植黄菖蒲 (Irispseudacorus), 美人蕉 (Cannaindica), 梭鱼草 (Pontederiacordata), 风车草 (Cyperusalterniflius) 和再力花 (Thaliadealbata) 等在室内预实验中证实了在高浓度污水中均可存活的植物, 植 株种植密度为 9 株 $/ \mathrm{m}^{2}$, 种植间距为 $0.3 \mathrm{~m}$. 为增强浮床的污染物净化能力和景观效果, 不同植物生态浮床进 行不同排列组合方式串联或并联后, 以固定针固定于桥墩或河岸护栏上. 试验植物约 2300 株, 其中美人蕉 床占 $40 \%$, 梭鱼草床占 $7 \%$, 再力花床占 $25 \%$, 风车草床占 $21 \%$, 黄菖蒲床占 $7 \%$.

\section{2 样品采集与测试}

采样方法: 从 2009 年 5 月至 2009 年 11 月, 选择河道中部长 $100 \mathrm{~m}$ 、河水流量变动范围为 $76.0-$ $135.0 \mathrm{~m}^{3} / \mathrm{h}$ 、面积为 $360 \mathrm{~m}^{2}$ 的强化生态浮床开展水质净化和生态修复试验研究 (图 1). 试验区每隔 $25 \mathrm{~m}$ 设置 样品采集点, 共 4 组 ( S1、S2、S3、S4), 并以河道中间无浮床区作为试验对照 ( S5、S6). 每月中旬定点采集水样 进行水样水质指标测定和浮游动物样品分类鉴定.

测试方法: $\mathrm{pH}$ 值测定采用 Model AB15 精密酸度计, 温度和溶解氧测定使用 YSI - 85 便携式溶解氧仪; 水体理化指标测定参照文献 [11];浮游动物的定性和定量采集和测定方法参照文献 [12-15].

\section{3 数据分析与统计}

采用 SPSS 13.0 统计软件分析对照区和示范区各种理化指标间、浮游动物种群间的差异以及浮游动物 丰度与水质因子之间的相关关系.

\section{2 结果与分析}

\section{1 污染物处理效果}

对对照区和浮床示范区各主要理化指标进行定期监测 (表 1), 研究期间示范区污染物浓度均呈下降趋 势, 总氮 $(\mathrm{TN})$ 、铵态氮 $\left(\mathrm{NH}_{4}^{+}-\mathrm{N}\right)$ 、总磷 $(\mathrm{TP})$ 、化学需氧量 $\left(\mathrm{COD}_{\mathrm{Cr}}\right)$ 、悬浮质 $(\mathrm{SS})$ 去除负荷分别为 $5.75 \pm 2.25$ 、 $5.93 \pm 1.65 、 0.15 \pm 0.05 、 50.37 \pm 10.67 、 17.20 \pm 6.15 \mathrm{~kg} /\left(\mathrm{m}^{2} \cdot \mathrm{a}\right)$, 与对照区相比, 强化型浮床对 $N 、 P$ 及有 机物均有显著的去除作用 $(P<0.05)$. 同时示范区溶解氧 (DO) 较对照区有显著提高 $(P<0.05)$, 表明强化 型浮床具有一定的增氧功能.

表 1 对照区与示范区水质情况比较

Tab. 1 The survey result of chemical and physical index in control area and study area

\begin{tabular}{lccccc}
\hline & \multicolumn{1}{c}{$\mathrm{TN}$} & \multicolumn{1}{c}{$\mathrm{NH}_{4}^{+}-\mathrm{N}$} & $\mathrm{TP}$ & \multicolumn{1}{c}{$\mathrm{COD}_{\mathrm{Cr}}$} & $\mathrm{SS}$ \\
\hline 对照区 $(\mathrm{mg} / \mathrm{L})$ & $36.88 \pm 9.66$ & $32.83 \pm 7.98$ & $1.13 \pm 0.30$ & $150.48 \pm 30.83$ & $69.50 \pm 38.46$ \\
示范区 $(\mathrm{mg} / \mathrm{L})$ & $32.62 \pm 8.59^{*}$ & $29.38 \pm 7.93$ & $0.94 \pm 0.28^{*}$ & $121.51 \pm 29.57^{*}$ & $55.93 \pm 34.47^{*}$ \\
去除负荷 $\left(\mathrm{kg} /\left(\mathrm{m}^{2} \cdot \mathrm{a}\right)\right)$ & $5.75 \pm 2.25$ & $5.93 \pm 1.65$ & $0.15 \pm 0.05$ & $50.37 \pm 10.67$ & $17.20 \pm 6.15$ \\
\hline
\end{tabular}

*表示 0.05 显著水平相关

\section{2 浮游动物种类组成}

对照区和示范区浮游动物种类组成结果显示 (表 2), 示范区浮游动物的种类较对照区呈极显著的增加 $(P<0.01)$. 示范区共鉴定浮游动物 4 类 49 种, 以轮虫类最多, 总计 33 种, 占种类总数的 $67.35 \%$; 原生动物 次之, 为 6 种, 占种类总数的 $12.12 \%$; 枝角类和桡足类较少, 各有 5 种, 各占种类总数的 $10.20 \%$. 各门类浮 游动物的数量与种类数, 示范区均比对照区明显增加, 表明浮床置人后利于浮游动物的生长. 河道内虽然仍 以颌花臂尾轮虫 (Brachionus calyciflorus)、镰状臂尾轮虫 (Brachionus falcatus) 和壶状臂尾轮虫 (Brachionus urceus) 等耐污的轮虫类为主,但示范区的种类已趋于丰富, 说明该区域水体正逐渐好转.

\section{3 浮游动物丰度变化}

示范区的浮游动物丰度较对照区显著增多 $(P<0.05)$, 修复伊始 ( 5 月) 其丰度就由对照区的 $1.22 \mathrm{ind} . / \mathrm{L}$ 上升到 4. 34ind. / L 这主要是因为浮床置人所带来的光照、溶解氧、水流等环境条件改变为浮游动物的生长 提供了更优越的环境, 使示范区浮游动物的丰度保持持续上升趋势, 至 8 月丰度达到了最高峰, 为 47. 19ind. /L, 并且主要以桡足类 (30.92ind. /L) 为主. 而从 9 月开始, 示范区中浮游动物的丰度略呈下降趋 势, 但仍显著高于对照区 $(P<0.05)$ (图 2). 这可能与 8 月后浮床植物的定期收割所引起的水体复氧率降低 
及水体扰动有关, 加之水温开始逐渐下降, 致使浮游动物丰度有所下降.

表 2 对照区与示范区浮游动物种类组成

Tab. 2 Species composition of zooplankton in control area and study area

\begin{tabular}{|c|c|c|c|c|}
\hline \multirow{2}{*}{ 门 类 } & \multicolumn{2}{|c|}{ 对照区 } & \multicolumn{2}{|c|}{ 示范区 } \\
\hline & 种类数 & 百分比(％) & 种类数 & 百分比 (\%) \\
\hline 轮虫类 Rotifer & 3 & 60 & 33 & 67.35 \\
\hline 原生动物 Protozoa & 1 & 20 & 6 & 12.25 \\
\hline 枝角类 Cladocera & 0 & 0 & 5 & 10.20 \\
\hline 桡足类 Copepoda & 1 & 20 & 5 & 10.20 \\
\hline 总计 & 5 & 100 & 49 & 100 \\
\hline
\end{tabular}

\section{4 浮游动物多样性指数变化}

就示范区和对照区浮游动物的 ShannonWiener 多样性指数 $\left(H^{\prime}\right)$ 和 Margalef 种类丰富度 指数 $(D)$ 进行分析, 结果具有较好的一致性. 两种指数均表现为示范区高于对照区 (表 3 ). ANOVA 分析结果显示, 除 Shannon-Wiener 多 样性指数 8 月份无显著差异以外 $(P>0.05)$, 其余各月两种指数在对照区与示范区均存在 显著性差异 $(P<0.05)$, 这表明随着浮床系统 的构建完成,示范区的水质得到了逐步的改 善,浮游动物群落多样性呈现逐步增加的 趋势.

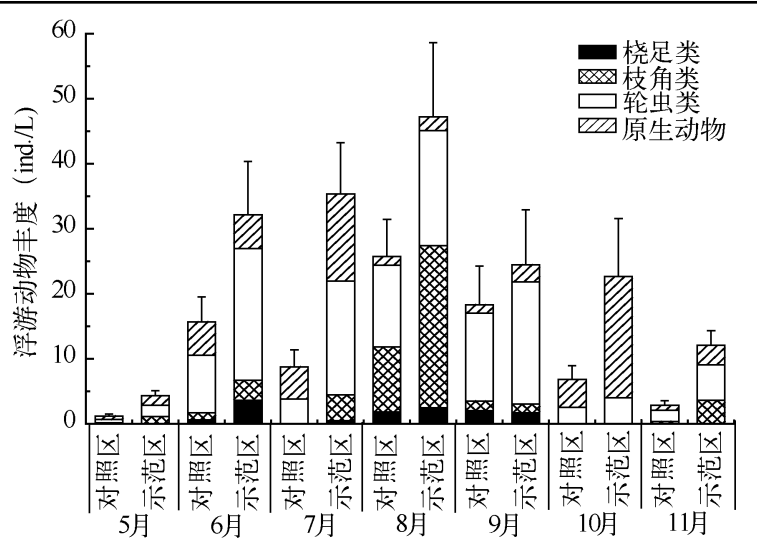

图 2 示范区和对照区浮游动物丰度变化

Fig. 2 Dynamics of zooplankton abundance in control area and study eara

表 3 浮游动物的生物多样性指数变化

Tab. 3 Variation of diversity index of zooplankton

\begin{tabular}{cccccc}
\hline \multirow{2}{*}{ 月份 } & \multicolumn{2}{c}{ Shannon-Wiener 多样性指数 $\left(H^{\prime}\right)$} & & \multicolumn{2}{c}{ Margalef 种类丰富度指数 $(D)$} \\
\cline { 2 - 3 } \cline { 5 - 6 } ～ & 对照区 & 示范区 & & 对照区 & 示范区 \\
\hline 月 & $0.39 \pm 0.04$ & $0.97 \pm 0.08^{*}$ & & $0.61 \pm 0.09$ & $1.67 \pm 0.11^{*}$ \\
7 月 & $1.53 \pm 0.09$ & $1.92 \pm 0.11^{*}$ & & $2.20 \pm 0.20$ & $1.79 \pm 0.08^{*}$ \\
8 月 & $1.19 \pm 0.14$ & $1.46 \pm 0.12^{*}$ & & $1.67 \pm 0.19$ & $2.66 \pm 0.23^{*}$ \\
9 月 & $2.10 \pm 0.09$ & $2.19 \pm 0.92$ & & $2.69 \pm 0.68$ & $3.43 \pm 0.10^{*}$ \\
10 月 & $1.44 \pm 0.07$ & $1.79 \pm 0.06^{*}$ & & $3.31 \pm 0.17$ & $4.04 \pm 0.31^{*}$ \\
11 月 & $0.91 \pm 0.15$ & $1.25 \pm 0.08^{*}$ & & $1.67 \pm 0.18$ & $2.41 \pm 0.16^{*}$ \\
均值 & $1.32 \pm 0.09$ & $1.69 \pm 0.14^{*}$ & & $3.40 \pm 0.18$ & $3.83 \pm 0.24^{*}$ \\
\hline
\end{tabular}

*表示 0.05 显著水平相关 


\section{5 浮游动物丰度与水质的关系}

水生生态系统是一个复杂的生态系统, 浮游动物的群落结构变化受到多种环境因素影响. 对示范区浮 游动物平均丰度与水质指标均值进行相关性分析 (表 4), 结果显示, 浮游动物的丰度与 DO、温度分别呈极 显著 $(P<0.01)$ 和显著 $(P<0.05)$ 正相关, 与 $\mathrm{NH}_{4}^{+}-\mathrm{N} 、 \mathrm{COD}_{\mathrm{Cr}}$ 呈显著负相关 $(P<0.05)$. 表明随着水体复氧率 的增加及污染物浓度的降低, 浮游动物的丰度逐渐上升 (图 2), 即随着水体环境的改善, 浮游动物的群落结 构逐渐恢复.

表 4 浮游动物丰度与理化因子相关性分析

Tabl. 4 The correlative analysis of physicochemical parameters and abundance of zooplankton

\begin{tabular}{lcccc}
\hline \multicolumn{1}{c}{ 浮游动物 } & 温度 $\left({ }^{\circ} \mathrm{C}\right)$ & $\mathrm{DO}(\mathrm{mg} / \mathrm{L})$ & $\mathrm{NH}_{4}^{+}-\mathrm{N}(\mathrm{mg} / \mathrm{L})$ & $\mathrm{COD}_{\mathrm{Cr}}(\mathrm{mg} / \mathrm{L})$ \\
\hline 轮虫 & 0.623 & 0.414 & -0.414 & -0.507 \\
枝角类 & 0.565 & 0.351 & -0.362 & -0.454 \\
桡足类 & $0.856^{*}$ & 0.607 & -0.579 & $-0.819^{*}$ \\
浮游动物总数 & $0.829^{*}$ & $0.774^{* *}$ & $-0.799^{*}$ & $-0.839^{*}$ \\
\hline
\end{tabular}

*表示 0.05 显著水平相关; $* *$ 表示 0.01 显著水平相关

\section{3 讨论}

\section{1 浮游动物种类组成和群落结构的变化}

作为水生生态系统的重要组成部分, 浮游动物的种类组成及数量消长与水质密切相关 ${ }^{[16]}$. 通常在清洁 型水体中浮游动物表现出种类多, 数量少的特点; 而在中度污染的水体中, 往往是耐污种类形成优势种群 (以较高数量出现) ; 重度污染 (包括有机和重金属污染) 的水体, 几乎所有的水生生物 (除了少数种类的细 菌) 都难以生存 ${ }^{[12]}$. 本文研究河流在开展修复工程前为重度污染河流, 仅存在少数几种喜好营有机污染水 体生活、且极耐低氧的浮游动物种类, 如颌花臂尾轮虫、並状臂尾轮虫、角突臂尾轮虫 (Brachionus angularis) 及桡足类中的广布种剑水蚤 (Mesocyclops leuckarti) 等, 说明其是以有机污染为主要特征的污染生态系统. 经 采用强化生态浮床技术对河流水质修复后, 浮游动物种类呈显著增加趋势, 逐渐演变为原生动物、多种轮 虫、桡足类和枝角类为主的群落结构 (表 2). 根据许木启 ${ }^{[17]}$ 关于浮游动物作为指示生物物种评价水环境质 量研究结果可知, 本研究河流的修复是一个从重度污染到清洁水体逐渐恢复的过程, 浮游动物种类也随着 水质的逐渐好转, 从耐污的原生动物向清水种类转变, 表明利用浮游动物种类多样性的变化开展水质监测 具有较好的指示作用.

一般来说, 健康群落的发展依赖于水质的改善, 在环境胁迫 (如污染) 条件下的水生生物群落, 其种类组 成及种类丰度呈减少趋势, 反之则增加 ${ }^{[18]}$. 试验初始, 示范区浮游动物群落结构整体上呈现轮虫 $>$ 原生动 物 $>$ 桡足类 $>$ 枝角类的趋势, 但随着水质的不断改善, 示范区原生动物和轮虫的优势地位已逐步弱化, 而枝 角类、桡足类的丰度值却表现出明显的增加趋势 (表 2), 并逐步形成稳定的群落结构, 这与许木启、陈光荣 等 ${ }^{[19-20]}$ 研究结果基本一致.

\section{2 浮游动物丰度的变化}

低溶解氧会使浮游动物的生长和繁殖受到抑制 ${ }^{[21]}$, 水体中溶解氧浓度直接决定着大多数水生生物的生 存状况 ${ }^{[22]}$. 浮床系统中水生植物根系输氧量远大于空气扩散所得氧量, 输氧速率也远比依靠空气向液面扩 散速率大 ${ }^{[23]}$. 因此, 根系输氧可减轻污染水体因溶解氧不足所带来的不利影响, 有利于浮游动物的生长, 使 示范区浮游动物丰度较对照区明显升高. 同时, 通过浮床植物根系生物膜的吸附、吸收以及生物代谢降解等 作用, 水体中氨氮及有机污染物浓度有效降低 ${ }^{[24-25]}$, 从而消减氨氮中非离子形式的氨对浮游动物的毒害作 用 ${ }^{[26-27]}$. 浮游动物生境得到有效改善, 进而引起浮游动物丰度发生显著变化, 显示出浮游动物种群变化与河 流水质改善间有着良好响应关系 (表 4). 此外, 水温也是影响浮游动物数量变化的极为重要的环境因子 ${ }^{[20]}$, 黄加祺等 ${ }^{[28]}$ 指出, 浮游动物丰度与温度有一定的相关性, 在温度较高时, 总个体数也达到高峰. 本研究温度 
与浮游动物生长相关性分析结果显示, 桡足类丰度、浮游动物总丰度与温度呈显著正相关, 其丰度随着温度 的升高而升高, 当温度下降时也呈下降趋势 (图 2). 但总体看来, 由于本研究地处热带亚热带地区, 采样时平 均水温大于 $20^{\circ} \mathrm{C}$, 较适合浮游动物的生长 ${ }^{[29]}$.

\section{3 浮游动物多样性指数的变化}

$\mathrm{H}^{\prime}$ 是群落中物种的种类和数量分布的一个重要指标, 多样性指数越高, 反映群落中物种越丰富、数量分 布越均匀 ${ }^{[30]}$. D 值能够较客观地反映水体的污染程度及变化趋势, D 值越高, 表示污染越轻; D 值越低, 表示 污染越严重 ${ }^{[19]}$. 本文研究的示范区经浮床作用后, 尽管水体污染未得到彻底改善,暂无寡污种类出现,但水 质已表现出好转趋势, 轮虫、桡足类、枝角类和原生动物的种类和数量都明显增加, 使得无论是 $\mathrm{H}^{\prime}$ 还是 $\mathrm{D}$ 值 均较对照区高 (表 3 ). 除了水质改善, 高的水生植物生物量也会使浮游动物多样性指数增加 ${ }^{[31]}$, 本研究浮床 植物一直保持着良好的生长状况, 生物量增加, 这可能也是导致浮游动物多样性增高的原因之一. 经浮床作 用后, 示范区 $\mathrm{H}^{\prime}$ 和 $\mathrm{D}$ 的均值分别为 3.12 和 1.62 , 运用 Shannon-Wiener 多样性指数对水质等级进行评判 ${ }^{[32]}$, 当 $\mathrm{H}^{\prime}$ 为 $1.0-2.0$ 时水质为受到中度污染; 而 Margalef 丰富度指数 D 为 2-4 时为中度污染, 结果基本一致, 表明水质尚属中度污染 ${ }^{[12]}$. 结果显示, 利用强化型生态浮床对重度污染水体进行修复, 已取得一定的效果; 而且证实了利用浮游动物生物多样性指数来评价水体修复措施的可行性和有效性.

综上所述, 利用强化生态浮床修复重污染河流, 引起了水体理化、生物环境的变化, 浮游生物对水体综 合环境的变化产生了积极的响应, 表现出明显的浮游动物恢复效能,虽然仍以耐污种类居多,但种类组成较 修复前已经发生根本变化; 浮游动物丰度与耗氧污染物 $\left(\mathrm{COD}_{\mathrm{Cr}} 、 \mathrm{NH}_{4}^{+}-\mathrm{N}\right)$ 呈现显著负相关 $(P<0.05)$, 而与 DO 浓度、温度分别呈极显著 $(P<0.01)$ 和显著 $(P<0.05)$ 正相关; 利用两种多样性指数评价水质修复效果 显示, 水体的污染程度正由重度污染向中度污染转变. 上述研究结果表明, 以浮游动物群落结构变化的参数 来分析水体修复效果具有可行性和有效性,一方面进一步证实应用强化生态浮床原位修复技术对改善污染 河流的水体质量发挥了重要作用,另一方面明显显示了利用浮游动物群落变化特征能够有效地监测和反映 受损害水生生态系统的生态治理与恢复效能. 这为我国河流的管理从以单纯改善水质为重点, 到河流整体 生态系统恢复的策略性转变提供了科学依据. 要掌握生态修复工程作用下浮游动物群落结构的变化规律需 要一个长期的过程, 本研究将对强化生态浮床修复技术所引起的水质及浮游动物的变化进行持续监测, 并 对完全没有浮床的区域进行设点采样, 以从更科学的角度评估、预测生态修复工程的有效性, 为强化生态浮 床技术修复重污染河流的可行性提供理论依据与指导.

致谢: 本研究在野外采样、理化因子测定及文章修改过程中得到李斌、于飞、陈纯兴、张晓萌、戴玉女、王铭等 人的协作与帮助,在此向他们表示衰心的感谢!

\section{4 参考文献}

[1 ] 胡洪营,何 苗,朱铭捷等. 污染河流水质净化与生态修复技术及其集成化策略. 给水排水, 2005, 31 (4) : 1-9.

[ 2 ] 罗固源,付永川,许晓毅等. 三峡库区次级河流污染整治的对策分析. 癌变. 畸变. 突变, 2007,19(3):209-211.

[ 3 ] 胡细全, 李兆华,王春秀等. 复合生态浮岛处理重度富营养化水体的静态试验研究. 湖北大学学报 (自然科学版), $2008, \mathbf{3 0}(3)$ : 309-312.

[ 4 ] Lee EJ, Kwon OB. The effects of floating islands planted with various hydrophytes for water quality improvement. Research Report of the Research and Education Center for Inlandwater Environment, Shinshu University, 2004.

[ 5] 李先宁, 宋海亮, 朱光灿等. 组合型浮床生态系统的构建及其改善湖泊水源地水质的效果. 湖泊科学, 2007,19 (4) : 367-372.

[ 6 ] Sun L, Liu Y, Jin H. Nitrogen removal from polluted river by enhanced floating bed grown canna. Ecological Engineering, 2009, 35(1) : 135-140.

[ 7 ] Hu GJ, Zhou M, Hou HB et al. An ecological floating-bed made from dredged lake sludge for purification of eutrophic water. Ecological Engineering, 2010, 36: 382-390.

[ 8 ] 李共国, 吴芝瑛, 虞左明. 引水和疏浚工程支配下杭州西湖浮游动物的群落变化. 生态学报, 2006,26 (10): 3508-3515.

[ 9 ] Mialet B, Gouzou J, Azémar F. Response of zooplankton to improving water quality in the Scheldt estuary (Belgium). Es- 
tuarine, Coastal and Shelf Science, $2011,93(1)$ : 47-57.

[10] Wu Z, Liu A,Zhang S. Short-term effects of drawing water for connectivity of rivers and lakes on zooplankton community structure. Journal of Environmental Sciences, 2008, 20 (4) : 419-423.

[11] 魏复盛. 水和废水监测分析方法:第四版. 北京:中国环境科学出版社,2002.

[12] 章宗涉,黄祥飞. 淡水浮游生物研究方法. 北京:科学出版社,1995.

[13] 王家楫,中国科学院水生生物研究所. 中国淡水轮虫志. 北京:科学出版社,1961.

[14] 蒋篎志, 堵南山. 中国动物志 (淡水枝角类). 北京:科学出版社, 1979 .

[15] 沈嘉瑞,戴爱云,张崇洲. 中国动物志:淡水桡足类. 北京:科学出版社,1979.

[16] 许木启. 从浮游动物群落结构与功能的变化看府河一一白洋淀水体的自净效果. 水生生物学报, 1996, 20(3): 212-220.

[17］许木启. 京密运河一北京排污河浮游动物群落变化与水质关系的研究. 环境科学学报, 1993,13(3):347-354.

[18 ] Xu M, Zhu J, Huang Y et al. The ecological degradation and restoration of Baiyangdian Lake, China. Journal of Freshwater Ecology, 1998, 13(4): 433-446.

[19] 许木启, 曹 宏, 王玉龙. 原生动物群落多样性变化与汉沽稳定塘水质净化效能相互关系的研究. 生态学报, 2000,20 (2):283-287.

[20] 陈光荣, 钟 萍, 张修峰等. 惠州西湖浮游动物及其与水质的关系. 湖泊科学, 2008,20(3):351-356.

[21] Sedlacek C, Marcus NH. Egg production of the copepod Acartia tonsa: The influence of hypoxia and food concentration. Journal of Experimental Marine Biology and Ecology, 2005, 318(2) : 183-190.

[22] 王晓明, 宋晓梅. 淮南市高塘湖浮游动物与水环境因子的相关性研究. 北京教育学院学报: 自然科学版, 2007,2 (5) $: 19-23$.

[23] Whitman RL, Nevers MB, Goodrich ML et al. Characterization of Lake Michigan coastal lakes using zooplankton assemblages. Ecological Indicator, 2004, 4(4) : 277-286.

[24] 成水平, 吴振斌, 况琪军. 人工湿地植物研究. 湖泊科学, 2002,14(2):179-184.

[25] 魏树和, 周启星. 有机污染环境植物修复技术. 生态学杂志, 2006,25(6): 716- 721 .

[26] Sarma S, Mangas-Ramírez E, Nandini S. Effect of ammonia toxicity on the competition among three species of cladocerans (Crustacea: Cladocera). Ecotoxicology and Environmental Safety, 2003, 55(2) : 227-235.

[27] Arauzo M. Harmful effects of un-ionised ammonia on the zooplankton community in a deep waste treatment pond. Water Research, 2003, 37(5) : 1048-1054.

[28] 黄加祺,洪幼环,朱长寿等. 福建南日岛海域浮游动物的分布. 东海海洋, 1997,4:47-53.

[29］金琼贝,盛连喜,张 然. 温度对浮游动物群落的影响. 东北师大学报(自然科学版),1991,4:103-111.

[30］方宏达,朱艾嘉, 董燕红等. 2005-2006 年珠江口浮游动物群落变化研究. 台湾海峡, 2009,28(1) :30-37.

[31] 胡春英. 不同湖泊演替过程中浮游动物数量及多样性的研究. 水生生物学报, 1999,23(3):217-226.

[32］沈暳芬,冯伟松,顾曼如. 河流的污染监测. 北京: 中国建筑工业出版社, 1995. 